\title{
A RACIALIZAÇÃO PELAS VOZES DAS PERSONAGENS DE LIMA BARRETO E ESMERALDA RIBEIRO E(M) UMA ANÁLISE DISCURSIVA
}

\author{
ADRIANA DOS REIS SILVA ${ }^{1}$ \\ SMED-PBH e Rede Formação EAD \\ adrianasier@yahoo.com.br
}

\begin{abstract}
Resumo. Este trabalho propõe uma reflexão acerca das personagens presentes nas obras de Lima Barreto (1922), Clara dos Anjos, e Guarde segredo (1998), criação de Esmerada Ribeiro. ‘̀ luz das formações discursivas segundo Michel Pêcheux (1997) investigou-se os padrões sociais instituídos pelas personagens das narrativas citadas, focando a Clara barretiana, seguidamente da personagem-narradora da trama de Esmeralda Ribeiro, além do cenário discursivo vivenciado pelos escritores. Verificou-se que ambas narrativas trazem a prerrogativa inferiorizante em relação ao negro, no entanto, Ribeiro através de uma escrita singular rompe com a voz estereotipada da representação da mulher negra, a resignação se esvai e um tom de combate surge através de sua escritura. Já, Barreto em sua época, reproduz o discurso da subalternidade, conformidade social, mas de forma insurgente, de modo a denunciar as atrocidades raciais traduzidas pela voz suburbana.
\end{abstract}

Palavras-chave: personagem; formação discursiva; ideologia; racialização.

\begin{abstract}
This work proposes a reflection about the characters present in the works of Lima Barreto (1922) Clara dos Anjos and Guarde Segredo (1998), written by Esmeralda Ribeiro. Regarding to the Discursive Formations according to Michel Pêcheux (1997) it was investigated the social standards instituted by the characters of the mentioned narratives, focusing on the Clara Barretiana, followed by the narrator-character of the Esmeralda Ribeiro plot, besides the discursive scenario experienced by the writers. It was verified that both narratives bring the lowering prerogative in relation to the black, however, Ribeiro through a singular writing breaks with the stereotyped voice of the representation of the black woman, the resignation is exhausted and a tone of fighting arises through its writing. Already, Barreto in his time, reproduces the discourse of subordination of the social conformity, but in an insurgent way to denounce racial atrocities, that is translated by the suburban voice.
\end{abstract}

Keywords: character; discursive formation; ideology; racialization.

\footnotetext{
${ }^{1}$ Doutora em Língua Portuguesa e Linguística pela Pontifícia Universidade Católica de Minas Gerais.
} 


\section{INTRODUÇÃO}

O presente trabalho busca à luz da análise do discurso materialista, com ênfase nas formações discursivas, investigar o perfil feminino de Clara dos Anjos da obra barretiana (1922), intitulada com o mesmo nome dessa personagem protagonista, e o da personagem do conto de Esmeralda Ribeiro "Guarde segredo" (1998), que traz em sua narrativa, também, uma jovem enamorada de um rapaz chamado Cassi Jones, como na escritura de Barreto; porém, essa moça, inominável pela voz narratária, apresenta um perfil diferente daquela retratada pela construção barretiana, como veremos no decorrer do estudo.

Para constituir o aporte teórico estabelecido nessa análise, considera-se a noção de formação discursiva segundo Michel Pêcheux (1997). Assim, objetiva-se nesse contexto contrapor as formações discursivas (FD) inscritas sob o posicionamento ideológico, histórico e social dos autores, sobretudo, os aspectos raciais presentificados em cada contexto, numa tentativa de apreensão do real. Pretende-se, ainda, confrontar a FD que envolve a criação barretiana (Clara dos Anjos) àquela de Esmeralda Ribeiro. Assim, busca-se entender as FDs de cunho raciais por meio da materialidade histórica que cada contexto pode vir a demonstrar.

\section{A NOÇÃO DE FORMAÇÃO DISCURSIVA E A SUA ESTRUTURAÇÃO A PARTIR DO REAL}

Para introduzir a noção de formação discursiva (FD) tomamos de empréstimo os estudos de Pêcheux (1997), que reconhece uma FD a partir de sua constituição, a qual se estabelece por

aquilo que numa formação ideológica dada, isto é, a partir de uma posição dada numa conjuntura dada, determinada pelo estado da luta de classes, determina o que pode e deve ser dito (articulado sob a forma de uma arenga, de um sermão, de um panfleto, de uma exposição, de um programa, etc.). (PECHEUX, 1997, p. 160)

A base do pensamento desse autor se constitui sob a interpelação do sujeito pela ideologia. As formações discursivas nesse contexto se compõem pelos diversos interdiscursos e, assim, possuem ideologias distintas no seu interior.

Para o autor, a ideologia indica através do "hábito" e do "uso", "o que é" e "o que deve ser" e isso, em alguns casos, por intermédio de desvios linguisticamente assinalados em meio ao preconceito e à constatação, funciona como dispositivo de "retomada do jogo". As evidências pelas quais "todo mundo sabe" o que é, por exemplo, um soldado, um operário, uma fábrica, uma greve, etc. são geradas pela ideologia. Essas certezas manifestas fazem que um enunciado/palavra diga o que realmente deseja dizer, sendo mascarado sob a "opacidade da linguagem", isto é, a materialidade do sentido contido nos léxicos e enunciados (PECHEUX, 1997, p. 159).

Assim, caráter material do sentido, mascarado por sua evidência transparente para o sujeito, consiste na sua dependência constitutiva daquilo que chamamos "o todo complexo das formações ideológicas” (PECHEUX, 1997, p. 160). Diante dessa 
afirmação, o autor busca especificar essa espécie de subordinação do sentido através do seguinte princípio: o sentido de uma palavra, expressão, proposição etc. não existe por si, isto é, em sua correspondência com a literalidade significante na qual é introduzido, sendo então estabelecido pelas posições ideológicas inscritas no jogo do processo social e histórico com os quais essas palavras, expressões, proposições etc. são confrontadas.

As FDs são, nessas circunstâncias, projeções, na linguagem, de certas formações ideológicas vigentes. Logo, o sentido de um estado de coisas só é adquirido a partir do posicionamento daqueles que o empregam, inscritos sob uma dada ideologia.

Pêcheux (1997) entende que qualquer formação discursiva dissimula, pela diafaneidade do sentido constituído por ela, sua dependência ao "todo complexo com dominante" das formações discursivas, enredado no complexo das formações ideológicas. A esse "todo complexo com dominante" das formações discursivas atribuise o nome de interdiscurso.

Diremos, nessas contradições, que é próprio de toda formação discursiva, dissimular na transparência do sentido que nela se forma, a objetividade material contraditória do interdiscurso, que determina essa formação discursiva como tal, objetividade material essa que reside no fato de que "algo fala" (ça parle) sempre "antes, em outro lugar e independentemente", isto é, sob a dominação do complexo das formações ideológicas. (PÊCHEUX, 1997, p. 162; destaque do autor)

Apreende-se que uma FD remete a algo relativo a uma memória discursiva constituída por um esquecimento determinante, com base no princípio de que todo discurso se manifesta na relação com a sua alteridade/exterioridade, ou ainda numa interação constitutiva com outros discursos.

O interdiscurso assinala o espaço discursivo e ideológico no qual se desenvolvem as formações discursivas sob as relações de subordinação, dominação e contradições existentes no âmbito enunciativo.

Orlandi (2010) afirma que pelo funcionamento das formações discursivas e do interdiscurso podemos apreender os mecanismos ideológicos para a constituição do sujeito e do sentido. A formação discursiva, enquanto conceito torna possível que sujeitos empíricos apreendam sentido de certas palavras, expressões etc. em um determinado período histórico.

Uma FD é, portanto, heterogênea a ela própria: o fechamento de uma FD é fundamentalmente instável, ela não consiste em um limite traçado de forma definitiva, separando um exterior e um interior, mas se inscreve entre diversas FDs como uma fronteira que se desloca em função dos embates da luta ideológica. (COURTINE; MARANDIN, 1981, p. 41)

Logo, uma formação discursiva pressupõe ser uma unidade heterogênea, indispensável àquilo que deve e pode ser dito em um dado momento da vida social humana. 
Por meio do conceito de FD intenta-se apreender como a estruturação real e ficcional dos objetos se articulam através da perspectiva do dizer sócio-ideológico de seus autores, assim como a materialidade enunciativa dos contextos vivenciados pelas personagens em questão.

Iniciaremos nossas primeiras análises pelo lugar social/empírico que cada um dos escritores assume num dado contexto discursivo-social brasileiro. Começaremos pela condição sociocultural Lima Barreto, seguidamente do posicionamento social, ideológico, histórico etc. apresentado pela escritora Esmeralda Ribeiro para tais reflexões.

Sobre Lima Barreto e as relações de classes pode-se dizer que sua época (idos do século XX) se baseia em determinados preceitos hierárquicos (status, situação econômica, cultural etc.) advindos da Europa, e o Brasil no que diz respeito às hierarquias revela algumas combinações que estão intimamente ligadas ao processo de formação das diferenças sociais brasileiras como a raça/a cor do indivíduo (não nos esqueçamos que Barreto era mulato), ou a classe social, preceitos inerentes ao etnocentrismo.

Em 1881 nasceu Lima Barreto. Ele cresceu sob panorama político e social marcado pela Abolição da Escravatura (1888) e a Proclamação da República (1889). Presenciou a sucessão de vários presidentes, como Afonso Pena (1909), Nilo Peçanha (1909-1910), entre outros. Ainda, assistiu a um período de crise no Brasil, com desempregos, reivindicações políticas, tudo isso concomitante à Primeira Guerra Mundial, tornando a situação brasileira ainda pior.

Logo, desse contexto emerge o escritor Lima Barreto, criando uma obra que evidenciará um período de saudosismo, de reforma, mas apresentando também, a irreverência das vanguardas, da psicanálise, da relatividade de Einstein, da Revolução Russa, da anarquia espanhola e dos sindicatos fascistas. (PRADO, 1980 apud BOSI, 1970, p. 342-343).

$\mathrm{Na}$ juventude, Barreto realizou seus estudos na Politécnica, nesse meio o jovem sentiu o preconceito de seus colegas, era o estranho entre os estudantes abastados. Já adulto, chamavam-no de negro, às vezes era tomado como bandido, devido a sua coloração de pele. Lima Barreto misturava-se com pessoas inusitadas, como prostitutas, viciados etc. (PRADO, 1999). O escritor era consciente da situação brasileira, ele a vivia, combatendo a desigualdade do país através de sua escritura, se tornando a voz dos "infelizes".

Encontraremos, em suas páginas íntimas, expressões de desalento, mas não de autocomiseração. Mesmo as alusões constantes ao problema da cor ou à adoração nacional pelos doutores, embora ligadas a experiências pessoais, voltam-se para fora, para a sociedade que conhece e sobre a qual testemunha. (LINS, 1976, p. 24)

Barreto mostra-se um tom descontente para com a sociedade, a literatura que ele cria fornece pistas para tal apreensão, vejamos: "a vida cara, enquanto os salários eram mais ou menos os mesmos anteriores. $\mathrm{O}$ descontentamento se fez e os pobres começaram a ver que, enquanto eles ficavam mais pobres, os ricos ficavam mais ricos" (BARRETO, 1956, p. 54). O autor, em sua incursão literária, busca promover reflexões sociorraciais e políticas. Ele ironiza, escarnece de uma sociedade nada convencional e democrática 
(como se observa pela voz de Linz, logo abaixo), e a elite de sua época não o perdoa por tal fato.

\begin{abstract}
As classes dominantes (e, com elas, amplos setores das classes dominadas, que refletem em grande parte a visão conservadora) são particularmente sensíveis no Brasil aos que as renegam de maneira ostensiva. Pareceu-me sofrer Lima Barreto, e creio não enganar-me, o efeito de uma ação difusa, um processo disfarçado, surdo, de sonegação (muito semelhante, por sinal, ao que entre nós marginaliza o negro). Acresce que os povos mostram-se sensíveis às idealizações. E Lima Barreto é talvez o autor brasileiro que nos viu até hoje com maior verdade e lucidez. (LINS, 1976, p. 12)
\end{abstract}

Sob tais circunstâncias, Lima Barreto, toma a literatura não como expressão, mas, principalmente, como "comunicação militante", palavra empregada pelo autor que "se engaja, tão ostensivamente quanto possível, com suas palavras e o que elas transportam, a mover, demover, comover, remover e promover" (LINS, 1976, p. 18). O autor, através de sua escrita, confronta a sociedade brasileira e é ignorado por ela.

O cenário sócio-histórico vivido pelo escritor conservou o domínio dos grandes latifúndios - os senhores de escravo. A formação social, nesse contexto, presentifica um processo de produção no qual as forças produtivas são movidas pelas leis escravagistas. Sob esse aspecto, Althusser (1983, p. 10), considera que em uma formação social iremos encontrar um movimento que "releva de um modo de produção dominante, podemos dizer que o processo de produção põe em movimento forças produtivas existentes em (dans et sous) relações de produção definidas". Logo, a relação de produção subsistente na nação brasileira defendia a coisificação do negro, determinante para um ideário racista.

Os pretos e descendentes de pretos, esses continuavam relegados, ao menos em certos textos oficiais, a trabalhos de baixa reputação, os negro jobs, que tanto degradam o indivíduo que os exerce, como sua geração. Assim é que, em portaria de 6 de agosto de 1771, o vice-rei do Brasil mandou dar baixa do posto de capitão-mor a um índio, porque "se mostrara de tão baixos sentimentos que casou com uma preta, manchando o seu sangue com esta aliança, e tornando-se assim indigno de exercer o referido posto". (HOLANDA, 1995, p. 56; destaque do autor)

Assim, a formação ideológica que perpetua no espaço o qual Lima Barreto transitou evidenciou crenças da inferioridade do negro. Tal prerrogativa efetiva $o$ condicionamento do indivíduo africano em solo brasileiro; desse modo o europeu consegue o respaldo da escravatura. Afinal, havia a necessidade de acreditar que o negro era "inferior", "subordinado" ao "branco", essa proposição reforçava a escravidão, pois sem ela não seria "possível num país cristão" haver um processo tão cruel de aprisionamento de um indivíduo (FERNANDES, 1972, p. 42).

Nota-se que a filiação discursiva de Lima Barreto se apoia, sobretudo, em diversas FDs de valores múltiplos, mas a que trata da racialidade, em especial, parece se destacar nessa época barretiana. O período discriminatório vivido por Barreto demonstra a iniquidade da relação branco-negro. Logo, tendo em vista que uma formação discursiva se estabelece por um sistema de relações linguísticas e interdiscursivas no qual acontecem 
os processos discursivos efetivos, os relatos intertextuais corroboram as diferenças entre os indivíduos. Tais fatos manifestos como esses inscritos na vida de Barreto revelam a racialidade desse tempo.

O olhar nesse instante se volta à posição que Esmeralda Ribeiro estabelece na sociedade brasileira. A escritora nasceu em São Paulo (1958) e integra a Geração Quilombhoje, atuante em atividades que combatem a racialização, além de construir por meio das tradições culturais africanas e afrobrasileiras uma literatura negra ${ }^{2}$. A partir de participações em seminários e congressos, a escritora objetiva incentivar a mulher negra a atuar mais no campo da literatura. Na década de 1980, Ribeiro participou de eventos e um merece destaque, observe:

[...] I e do II Encontros de Poetas e Ficcionistas Negros Brasileiros: "quero falar de 'nós' porque o tempo sempre nos deixou atrás das cortinas, camuflando-nos geralmente em serviços domésticos. Agora, o tempo é outro. É desse tempo que vou falar. (Criação crioula, nu elefante branco, p. 59)

Percebe-se que a escritora atua na disseminação de ideias e reflexões acerca da questão racial no Brasil. Segundo o Portal UFMG de Literatura Afro-Brasileira, Ribeiro apresenta uma obra de temática variada, com "tom de denúncia e a construção de uma literatura que se atrela à realidade político-social brasileira", marcas que mostram a criticidade da autora em "relação ao que está em torno de si mesma, ao mundo que a cerca"4.

Assim, em uma escritura de teor engajado, Esmeralda Ribeiro, revela as mazelas das pessoas invisíveis, aquelas que margeiam a sociedade, fazendo ecoar a voz da opressão daqueles que sempre lutam, mas como diria Lima Barreto serão vistos como “infelizes”. Sob esse tom a autora consegue 'desemudecer' um grupo marginalizado como ela mesma revela pelo trecho abaixo.

O meu trabalho literário está dirigido a todas as pessoas que: - têm gingado no andar, estão nos guetos da vida e fazem do espelho sua própria realidade: de beiços, ventas, rugas mentais cravadas em episódios seculares impõem-se o enigma da resistência, não só como luta coletiva, mas também individual e sempre lutaram e sabem que o perigo está a cada esquina de boca aberta acuando suas vítimas. Os débeis racistas $[\ldots]$ pensando serem sábios paternalizam-me, analisamme e trazem em suas línguas de porcelana o mapa da minha descoberta. $[\ldots]$ ingenuamente proferem ébrios discursos sobre a minha literatura, deixando zumbi/zumbindo em meu passado. (CADERNOS NEGROS $8,1985$, p. $7-8)$

Sob tais apontamentos nota-se que Esmerada Ribeiro apresenta um tom perspicaz acerca do processo social, político e cultural do Brasil, e como negra, parece assumir uma

\footnotetext{
${ }^{2}$ Conforme Portal UFMG. Literatura Afro-Brasileira. Disponível em: www.letras.ufmg.br/literafro. Acesso em 10 set. 2014.

${ }^{3}$ Conforme Portal UMFG. Literatura Afro-Brasileira. Disponível em: www.letras.ufmg.br/literafro. Acesso em 10 set. 2014.

4 Conforme Portal UMFG. Literatura Afro-Brasileira. Disponível em: http://www.letras.ufmg.br/literafro/data1/autores/61/esmeraldacritica01.pdf. Acesso em 10 set. 2014.
} 
FD antirracial, além de outras que promovam a inserção do Outro (pobre, negro etc.) que buscam por um lugar melhor no mundo. A sua escritura nos propicia tal apreensão, como por exemplo, em "Guarde segredo", como observaremos adiante.

A noção de FD, segundo a base proposta por Pêcheux, se realiza sob as regularidades particulares de posições de classes definidas em função de embates ideológicos constitutivos de uma situação histórica, política e social. $\mathrm{O}$ autor postula que todo discurso se inscreve em certa FD, que é dominante a esse discurso; entretanto, essa FD só se estabelece em relação a sua exterioridade, ou seja, através de outras FDs determinantes para esse mesmo discurso. Nessa perspectiva, encontra-se o interdiscurso, delimitando as vinculações possíveis entre as FDs, possibilidade que se instaura pela reconfiguração que as FDs sofrem em função das condições históricos, sociais e ideológicas particulares.

O nível da constituição do sentido, nessas circunstâncias, é evocado através de termos, léxicos etc., que surgem por meio de outros; são as posições ideológicas sob um contexto sócio-histórico que definem o que dizer, ou ao menos, aquilo que se pretende dizer (PECHEUX, 1997). É a partir dessa noção, que se considera certos posicionamentos ideológicos dos sujeitos de ficção presentes tanto em Barreto como em Ribeiro.

Neste momento, contemplam-se as peculiaridades da personagem Clara dos Anjos presente na obra de Barreto, em contraposição à personagem de Ribeiro. O quadro abaixo mostra, de um modo geral, a condição de Clara na obra barretiana:

\begin{tabular}{|c|c|c|c|c|}
\hline \multicolumn{5}{|c|}{ Romance: Clara dos Anjos } \\
\hline Personagem & $\begin{array}{c}\text { Cor } \\
\text { (Etnia) }\end{array}$ & Ambiente & Espaço & Participação do sujeito ficcional \\
\hline Clara dos Anjos & Mulata & $\begin{array}{c}\text { Nenhuma ascensão social/Boa } \\
\text { conduta moral / Amorfa }\end{array}$ & $\begin{array}{c}\text { Subúrbio do Rio } \\
\text { de Janeiro }\end{array}$ & Principal/Heroína \\
\hline
\end{tabular}

Quadro 01: Caracterização de Clara (Romance).

Clara dos Anjos, nesse contexto, é de uma família humilde, sem posses, porém honesta e trabalhadora. Trata-se de uma jovem prendada. Saia de casa somente com a mãe ou com alguém de confiança da família.

Engrácia, cujos cuidados maternos eram louváveis e meritórios, era incapaz do que é verdadeiramente educação. Ela não sabia apontar, comentar exemplos e fatos que iluminassem a consciência da filha e reforçassem-lhe o caráter, de forma que ela mesma pudesse resistir aos perigos que corria.

A mulher de Joaquim dos Anjos tinha a superstição dos processos mecânicos, daí o seu proceder monástico em relação à Clara. (BARRETO, 1998, p. 54)

\footnotetext{
${ }^{5} \mathrm{O}$ narrador se refere à Clara como portadora de uma natureza "amorfa, pastosa que precisava mãos fortes que modelassem e fixassem" (BARRETO, 1998, p. 90).
} 
Diante de tantos desvelos, Clara não adquire experiências sobre a vida, fato que a aliena dos dissabores do mundo, acentuando sua ingenuidade perante as atitudes humanas.

A personagem teve um pouco de estudo, mas isso não foi o suficiente para se tornar uma pessoa independente, ou até mesmo crítica diante das atribulações que a vida lhe proporcionou. Nesse sentido, o narrador aponta que: "A idade, o sexo e a falsa educação que recebera, tinham muita culpa nisso tudo; mas a sua falta de individualidade não corrigia a sua obliquada visão da vida” (BARRETO, 1998, p. 90).

Sobre os atributos físicos, Clara, pode ser descrita como pardo-clara e cabelos lisos.

Crescera em um ambiente em que a predominância musical era efervescente: seu pai era habituado às modinhas, tanto que "enfumaçara a sua pequena alma de rapariga pobre e de cor com os dengues e o simplório sentimentalismo amoroso dos descantes e cantarolas populares" (BARRETO, 1998, p. 42).

As canções faziam parte do mundo musical de Clara, ela ouvia as modinhas cantadas por seu pai e os amigos deste: "o mundo se lhe representava como povoado de suas dúvidas, de queixumes de viola, a suspirar amor” (BARRRETO, 1998, p. 90).

A maturidade e entendimento eram poucos acerca de sua condição feminina perante a sociedade patriarcal e machista na qual ela vivia. A moça se torna indefesa na presença de qualquer pessoa de índole duvidosa, como Cassi Jones.

Já a suposta (hipotética) Clara de Esmeralda Ribeiro - pois a personagemnarradora não se nomeia, deixa apenas as marcas textuais corroborarem tal conjectura "Ficamos conversando horas e horas. Depois de alguns dias começamos a namorar. Cassi Jones era sardento, usava goma nos cabelos e andava bem vestido (RIBEIRO, 1998, p. 69).

Logo, abaixo mostramos como a personagem de "Guarde segredo" se apresenta:

\begin{tabular}{|c|c|c|c|c|}
\hline \multicolumn{5}{|c|}{ Conto: Guarde segredo } \\
\hline Caracterização do sujeito ficcional & Participação \\
\hline $\begin{array}{c}\text { A personagem de } \\
\text { Guarde Segredo }\end{array}$ & Negra & Ambiente & Espaço & Principal/Heroína \\
\hline
\end{tabular}

Quadro 02: Caracterização da personagem do Conto.

A jovem recriada por Ribeiro é corajosa e não aceita a resignação da sua condição feminina; como revela-se pela voz narratária, ela não "deixa por menos", o desabafo impiedoso da jovem pode ser observado no trecho abaixo.

[...] Então fui ao mercado e comprei uma faca... Procurei igual uma louca o desgraçado. Encontrei-os na saleta de um hotelzinho... Não teve 
tempo de reagir. Foram tantas facadas...! Parei quando caiu aos meus pés. (RIBEIRO, 1998, p. 71)

Martins (2007, p. 65) em seus estudos nos mostra "que próprio ato de narrar tornase veículo de transformação da memória do narrado", resgatado pela lembrança como uma transformação, uma transgressão à narrativa primeira - que se trata da obra barretiana. Para a estudiosa a personagem-narradora do conto de Esmeralda cumpre "um duplo papel, como personagem de um enredo ficcional, em cuja face se projetam e se deslocam tanto um modelo trágico exemplar, quanto a própria história literária e social que o sustenta”.

Essa moça, assim como a Clara barretiana, nasceu no Rio de Janeiro e como ela, conhecia o subúrbio, teve como amante Cassi Jones, "sardento, usava goma nos cabelos" (RIBEIRO, 1998, p. 70). Essa ficção traz também para seu enredo Lima Barreto como um velho conhecido da avó da protagonista e esse dá o tom ao grande final dessa trama. A jovem não termina a narrativa como na ficção barretiana, com a resignação de não ser nada nessa vida. Agora, atordoada com a situação inusitada, a protagonista de "Guarde Segredo" não tem dó de ninguém, tampouco dela mesma. Mata aquele que a trai.

\section{DISCUSSÃO E ANÁLISES FICCIONAIS}

Uma formação discursiva define-se em função de sua dependência constitutiva do "todo complexo com dominante", ou seja, do interdiscurso (PÊCHEUX, 1997, p. 162), que traz à tona o lugar da constituição do sentido. Desse espaço apreende-se o efeito de pré-construído "sempre-já-aí da interpelação ideológica" e a articulação constituída pelo "sujeito em relação com o sentido", que são evocados através do processo da interdiscursividade (PÊCHEUX, 1997, p. 164). O pré-construído faz alusão a determinadas certezas manifestadas pelo sujeito através de sua enunciação, isto é, "o que cada um sabe e simultaneamente o que cada um pode ver" (BRANDÃO, 2004, p. 49).

É sob essa perspectiva, que se busca entender a formação discursiva a qual envolve a personagem Clara dos Anjos, inscrita no romance de Lima Barreto, tendo em vista o lugar assumido por esse sujeito ficcional em um dado momento histórico e social da narrativa barretiana.

O momento histórico do contexto expresso por Clara remete aos idos de 1900. A personagem se projeta sob uma classe social baixa, um estado de pobreza, e ainda, apresenta a condição física de mulata. Nesse espaço discursivo do romance barretiano seguem alguns recortes, visando demonstrar o caráter socioinstitucional e ideológico conferido a Clara, como se pode observar abaixo.

Narrador:

Na sua vida, tão agitada e tão variada, ele sempre observou a atmosfera de corrupção que cerca as raparigas do nascimento e da cor de sua afilhada; e também o mau conceito em que se têm as suas virtudes de mulher. A priori, estão condenadas; e tudo e todos pareciam condenar os seus esforços e os dos seus para elevar a sua condição moral e social. (BARRETO, 1998, p. 42; destaque meu) 
A passagem acima mostra o pensamento de Marramaque (padrinho de Clara dos Anjos e amigo íntimo da família) sua em relação às moças de cor, como é o caso de Clara. Pelo excerto observa-se os primeiros aspectos de uma FD de superioridade racial que assinala aquilo que se pode dizer em relação a esses indivíduos: "[...] atmosfera de corrupção que cerca as raparigas do nascimento e da cor de sua afilhada [...]" (BARRETO, 1988, p. 42); bem como a FD de discriminação de cor, revelando o teor discricionário sobre a mulher negra - "[...] o mau conceito em que se têm as suas virtudes de mulher [...]" (BARRETO, 1988, p. 42) Por fim, a sentença final desse episódio: " $A$ priori, estão condenadas; e tudo e todos pareciam condenar os seus esforços [...]" (BARRETO, 1988, p. 42) mostra-nos o caráter determinista desenhado pela FD de superioridade racial (não apenas de reconhecimento do lugar de superioridade, mas também de atribuição do lugar de inferioridade ao outro, e/ou autoafirmação enquanto um ser social).

O tratamento singular de superioridade racial configurado acima, se pauta pela reflexão advinda de Marramaque, um mulato, padrinho da jovem Clara; dado que demonstra o assujeitamento e/ou a interpelação sofrida por esse indivíduo perante um discurso discriminatório presentificado por uma formação ideológica racializante, que ele reproduz, mesmo sendo um representante da classe que sofre o preconceito.

O personagem Marramaque viveu no meio de "rodas de gente fina" (BARRETO, 1988, p. 40); mesmo tendo pouca instrução e apresentando uma saúde debilitada, presenciou um período de:

Plena escravatura, se bem que nos fins, mas a antiga Província do Rio de Janeiro era próspera e rica, com as suas rumorosas fazendas de café, que a escravaria negra povoava e penava sob os açoites e no suplício do tronco. (BARRETO, 1998, p. 36)

É relevante reiterar que esse contexto social expressa a riqueza brasileira que se constrói sobre o trabalho escravo, o que pressupõe uma ideologia racista, que se pauta em uma prática social que tem como base a dissimetria entre a relação branco-negro, perpetuando a desigualdade da estrutura social.

Verifica-se que desse espaço surge uma avaliação depreciativa a respeito das mulheres, principalmente, das afrodescendentes e pobres. $\mathrm{O}$ mundo projetado pela história ficcional de Clara desenvolve padrões discriminantes, revelando uma sociedade cujas relações sociais de seus membros se estabelecem de maneira restrita, na qual - as ideias da classe dominante são preponderantes e projetam: a inferioridade do negro, do pobre, a submissão feminina etc.

No próximo episódio, Clara, parece começar a entender sua posição na sociedade revelada pela narrativa barretiana, como se observará abaixo:

Narrador:

Uma dúvida lhe veio; ele era branco; e ela, mulata. Mas que tinha isso? Havia tantos casos... Lembra-se de alguns... E ela estava tão convencida de haver uma paixão sincera no valdevinos, que, ao fazer esse inquérito, já recolhida, ofegava, suspirava, chorava; e os seus seios duros quase estouravam de virgindade e ansiedade de amar. (BARRETO, 1998, p. 56; destaque meu) 
Contudo, o entendimento revelado pela jovem Clara está longe de representar uma ruptura da FD de superioridade racial, quando muito reproduz a extensão daquilo que é dito (ou imaginado) acerca do discurso racial: "Uma dúvida lhe veio: ele era branco; e ela, mulata [...]" (BARRETO, 1998, p. 56). Há nesse contexto certo conformismo diante da incerteza colocada pelo posicionamento da cor do sujeito, que se traduz pelo enunciado: “[...] já recolhida, ofegava, suspirava, chorava [...]” (BARRETO, 1998, p. 56).

Nesse momento percebe-se o efeito do encadeamento do pré-construído àquilo que todos já conhecem acerca da história social/cultural brasileira: a relação escravocrata implicou o processo racializante, estabelecendo a segregação entre brancos e negros. A personagem se ilude ao pensar que poderia ter um relacionamento normal com um homem branco, as determinações históricas no Brasil nos confirmam esses dados: "E é porque há essa ligação que as filiações históricas podem-se organizar em memórias, e as relações sociais em redes de significantes." (PÊCHEUX, 1997, p. 54). A ideia do inferiorização do sujeito negro cristalizou-se no imaginário social brasileiro.

Memmi, sob tais ponderações assevera que o sujeito acaba por reproduzir os padrões de dominação em que vive, traduzidos aqui, em termos das FDs que são apontadas mais acima, já que é através delas que os sujeitos exteriorizam as marcas profundas da discriminação. Nesse caso, Clara, ao tentar ignorar a separação social estabelecida pela diferença de cor entre ela e Cassi Jones, se convence da superioridade branca e busca viver dentro dos padrões dessa sociedade, como destacamos pela força de FD inferioridade racial (é a partir dela que discursos de submissão, de conformismo, de aceitação de papeis subalternos difundidos numa sociedade); como ratificado nas palavras de Memmi:

O colonizado se perde no "outro", se aliena. Tentará, pois, de acordo com a lógica desse movimento, levar a alienação às últimas consequências, tornando-se ele próprio um colonialista, casando-se entre os representantes da metrópole, por exemplo. (MEMMI, 1977, p. 08 ; destaque do autor)

Sobre esse cenário, parece-nos que o padrão ideológico da superioridade branca, o qual envolve o discurso circunscrito por Clara, revelando a inércia e o desconsolo dela perante um destino que não seria modificado, cabendo a ela aceitar sua mísera condição social e cultural. Essa postura aparece circunscrita na determinação da FD de inferioridade racial que caracteriza a imposição desse lugar subalterno, conforme destacado no trecho abaixo.

Narrador:

A filha do carteiro, sem ser leviana, era, entretanto, de um poder reduzido de pensar, que não lhe permitia meditar um instante sobre o destino, observar os fatos e tirar ilações e conclusões. A idade, o sexo e a falsa educação que recebera, tinham muita culpa nisso tudo; mas a sua falta de individualidade não corrigia a sua obliquada visão da vida. (BARRETO, 1998, p. 90; destaque meu)

Logo, ““[...] um poder reduzido de pensar [...] não lhe permitia meditar [...] sobre o destino [...]" (BARRETO, 1998, p. 90), nem ao menos “[...] observar fatos e tirar ilações e conclusões." (BARRETO, 1998, p. 90), são expressões que ocupam lugares de opressão 
racial numa sociedade. E são elas que condenam Clara a um lugar de submissão, à condição de que ela não dava conta de perceber e compreender as coisas mundanas, a sua educação pressupunha apenas as seguintes obrigações: cuidar da casa e dos filhos.

Clara:

A seguir o plano narrativo, expõe a infeliz condição social e moral da personagem

\author{
Narrador: \\ O bonde vinha cheio. Olhou todos aqueles homens e mulheres... Não \\ haveria um talvez, entre toda aquela gente de ambos os sexos, que não \\ fosse indiferente à sua desgraça... Ora, uma mulatinha, filha de um \\ carteiro! O que era preciso, tanto a ela como às suas iguais, era \\ educar o caráter, revestir-se de vontade, como possuía essa varonil \\ Dona Margarida, para se defender de Cassis e semelhantes, e bater- \\ se contra todos os que se opusessem, por este ou aquele modo, \\ contra a elevação dela, social e moralmente. Nada a fazia inferior às \\ outras, senão o conceito geral e a covardia com que elas o admitiam... \\ $[\ldots]$ \\ Dona Margarida relatou a entrevista, por entre o choro e os soluços da \\ filha e da mãe. [...] Clara ergueu-se da cadeira em que se sentara e \\ abraçou sua mãe, dizendo, com um grande acento de desespero: \\ Clara: \\ - Mamãe! Mamãe! \\ $[\ldots]$ \\ - Nós não somos nada nesta vida! \\ (BARRETO, 1998, p. 133; destaque meu)
}

Clara, ao final de sua história, observa não ter valor, nenhuma perspectiva de vida adequada a aguardava na sociedade preconceituosa na qual se inscrevia. Ainda que a visão da personagem possa ter o teor de uma avaliação crítica da sociedade em que vivia, o seu posicionamento diante da situação reflete o que estamos caracterizando pela FD que implica a inferioridade, o sujeito sob a condição de negro torna-se rejeitado perante a outra classe social (branca), a qual representa os padrões culturais vigentes.

Ao dizer que “[...] não somos nada nessa vida!" (BARRETO, 1998, p. 133), a personagem Clara revela que sua condição econômica e de cor eram algo determinante na sociedade vigente da época. Esse fato reforça a ideia da imobilidade social de Clara, dado que se torna preponderante na construção de um modelo comportamental de inferioridade, de conformismo por parte dessa personagem, confirmando a FD de inferioridade racial.

A partir das questões mostradas, percebe-se que os atos enunciativos que circunscrevem Clara adquirem uma estabilidade referencial a partir de certa conjuntura histórica e social, e se apoiam em saberes instituídos e legitimados no circuito social brasileiro, revelados pelas posições discriminatórias em relação ao Outro (quer seja negro/mulato/afrodescendente).

Um problema que é bastante evidente no Brasil, [...] é das relações entre negros puros e mulatos. Muitas vezes o negro se ressente do que os mulatos têm de sangue branco, vendo-os, pelo menos em parte, como membros da raça que oprimiu o negro. Um outro sentimento [...] é o da 
vergonha por parte do negro, reconhecendo que os primeiros mulatos foram fruto de violentações dos brancos contra as mulheres escravas, geralmente à força ou sem consentimento delas. [...] o mulato permanece como símbolo de traição forçada imposta ao macho africano. [...] Seu sangue negro o impede de ascender a uma posição de igualdade social com brancos, enquanto seu sangue branco o separa dos negros, o que muitas vezes o infelicita. (RABASSA, 1965, p. 440)

As FDs apresentadas pelo contexto concorrem a uma ideologia racista e estabelecidas por estruturas e posicionamentos socioculturais, além de avaliações depreciativas que circulam no meio brasileiro acerca do sujeito de cor, nos permitem configurar a condição de vida de Clara e a relação inferiorizante que esta estabelece com a sociedade de sua época. Clara carrega fisicamente o estigma do preconceito, sendo ainda descrita como "amorfa" e/ou apagada, apática, por não ter expressividade, o que direciona para um pré-construído que fornece uma realidade legitimadora para as FDs sob as quais ela se acha vinculada. Essa problemática em torno do negro se apoia nos modelos evolucionistas e social-darwinistas que são introduzidos no Brasil em meados de 1870, como forma de justificar teoricamente as práticas imperialistas de dominação. (SCHWARCZ, 1993, p. 30). Os conceitos da obra de Darwin servem de análises para o comportamento humano, assim como para questões acerca da seleção humana e social.

Conceitos como "competição", "seleção do mais forte", "evolução" e "hereditariedade" passavam a ser aplicados aos mais variados ramos do conhecimento: na psicologia, com H. Magnus e sua teoria sobre as cores, que supunha uma hierarquia natural na organização dos matizes de cor (1877); na linguística, com Franz Bopp e sua procura das raízes comuns da linguagem (1867); na pedagogia, com os estudos do desenvolvimento infantil; na literatura naturalista, com a introdução de personagens e enredos condicionados pelas máximas deterministas da época, para não falar da sociologia evolutiva de Spencer e da história determinista de Buckle. No que se refere à esfera política, o darwinismo significou uma base de sustentação teórica para práticas de cunho bastante conservador. (SCHWARCZ, 1993, p. 56; destaque da autora)

Dessa forma, parece-nos que a FD da inferiorização racial aqui tratada pela voz (ou o posicionamento) do sujeito-autor Lima Barreto, traz a prerrogativa de denúncia racial ao retratar o modo de ser de Clara. Lima Barreto não quer endossar a FD da inferiorização, mas sim combatê-la.

Nesse momento, o foco recai em outra luta, a demonstrada pelo sujeito-autor de Esmeralda Ribeiro, que também busca tal nuance, isto é, quer dar voz aqueles que estão a margem da sociedade, fazendo assim o 'bom' combate.

A narradora-personagem de Esmeralda Ribeiro não tem um caráter fragilizado, ela é imperativa e não sucumbe as lágrimas como a Clara da criação barretiana. Quando abordada na rua pela mãe de Cassi Jones que a ultraja e a humilha, dizendo: "você é a quinta negra que o meu filho deflorou e também não vai ficar com ele. Neste exato momento está com outra garota" (RIBEIRO, 1998, p. 70), a protagonista não aceita os desaforos da mãe de Cassi, ela se rebela, devolvendo, por exemplo, a cusparada na cara que a "sogra" havia lhe dado. 
Martins (2007, p. 66) comenta em seu trabalho que a protagonista de Ribeiro não "veste o papel de vítima sacrificial", fato que a desfigura do "papel e destino do seu prétexto". Para a autora a protagonista do conto

[...] se livra do namorado pervertido e enfrenta, com altivez, o discurso racialista da ex-futura sogra. No jogo intertextual e na fricção entre o texto exemplar da tradição literária e sua rasura, a narrativa de Esmeralda caligrafa um outro autógrafo na escrita do corpo feminino, assim como na escrita-corpus da literatura. (MARTINS, 2007, p. 66)

Assim, infere-se nesse caso, uma FD de cunho subversivo, a jovem a é incisiva: "Odiei aquela mulher e seu querido filho" (RIBEIRO, 1998, p. 70) e assim vai até as últimas consequências de seu envolvimento amoroso, sem submissão amorosa, nem medo, ela mata Cassi Jones a facadas.

Ao apontar a narradora-personagem de Esmeralda Ribeiro como a "quinta negra" já desonrada pelo filho, a mãe de Cassi Jones, evidencia A FD de preconceito. Contudo, a passionalidade da personagem de Ribeiro revela-se numa singularidade espetacular que pode ser notada por meio da atitude impulsiva da garota ao violar a lei, transgredindo um bem maior, que é a preservação da vida humana.

Entre a Clara barretiana e a personagem delineada por Ribeiro há um espaço temporal significativo, dado que como aponta Martins (2007) promove a rasura entre esta e aquela. No conto de Esmeralda Ribeiro a voz dada à personagem insufla o desejo do impossível, o tom aqui ocorre pela autoria e voz feminina; diferentemente da escritura de Barreto que se faz por uma ótica masculina, através de um narrador onisciente, que obviamente nos mostra a visão patriarcal de uma época cuja voz predominante certamente pertencia aos homens.

A mulher no contexto criado por "Guarde segredo", como afirma Neves (2009, p. 51) torna-se "objeto de uma escrita e não sujeito dela". Para este autor, Ribeiro se posiciona a partir de seu lugar de pertencimento, isto é, pelas experiências que ela viveu. "Como mulher esta sujeita aos mesmos problemas enfrentados pela protagonista", aponta Neves $(2009$, p. 51).

Outra divergência entre a Clara barretiana e a protagonista de Esmeralda Ribeiro é que esta tem livre acesso pela cidade, vive longe dos pais e sob a proteção da avó. Além disso, ela não tinha um poder reduzido de pensar como a Clara de Lima Barreto: [...] não lhe permitia meditar [...] sobre o destino [...]" (BARRETO, 1998, p. 90). A personagem de Ribeiro confessa que seu pouco sentimento por Cassi: "não o amava, mas não conseguia resistir a todo aquele charme" (RIBEIRO, 1998, p. 71). Ela não se vitimiza como a Clara de Barreto, age de um modo transformador sobre seu destino.

A fala da avó Olivia "Nós não devemos aceitar o destino com resignação" (RIBEIRO, 1998, p. 72) demonstra-nos uma FD antirracial. Não existe mais a submissão, o caráter descontente e agressivo de protagonista desse conto se liberta e deixa de aceitar resignada sua condição feminina, e tampouco, a de cor.

Nesse contexto, a personagem narradora de Ribeiro (1998) ocupa um lugar de uma instância de transformação, ela fará de seu destino o que quer, realizando-o a sua maneira. Assim, a jovem rompe com o estereótipo da negra fragilizada que aparece na 
obra de Barreto. Os tempos são outros, a narradora criada por Ribeiro (1988) ressurge como uma resposta a algo que Lima Barreto presenciou em seu tempo, a superioridade branca. Esse fato na atualidade, não mais tem um caráter tão determinista quanto o de outrora.

A voz narrativa, nessa instância, assume outra perspectiva e rompe com a conformidade de "não valermos nada nessa vida", a fala de Lima Barreto, personagem (re)criado na narrativa de Esmeralda Ribeiro nos dá esse tom: “- Bravo! Esse era o outro final que eu queria para o cafajeste do Cassi Jones” (RIBEIRO, 1998, p.72). Fato inusitado se comparado a atitude da Clara barretiana.

\section{CONSIDERAÇÕES FINAIS}

A personagem Clara dos Anjos de Barreto se constitui sob uma configuração negativa à qual os negros e/ou mulatos se associam no contexto ideológico brasileiro. Por isso, o discurso a partir do qual Clara se apresenta, emerge em relação a certo domínio da memória marcado pela ideia da inferioridade do negro perante o branco e mostra a posição dessa personagem se estabelecendo enquanto sujeito, revelando formações discursivas que reiteram não só o seu reconhecimento da inferioridade racial do negro, como os processos de discriminação a que é submetido na sociedade.

O contexto social brasileiro atribui um caráter depreciativo ao ser negro (a) e/ou mulato(a), dado que corrobora para a violência simbólica que envolve esses sujeitos. Contudo, Esmeralda Ribeiro retoma isso num contexto atual, modificado pelo surgimento heterogêneo de núcleos de resistência que lutam contra a manutenção estereotipada da representação da mulher na sociedade brasileira, fato que adquire vida através do poder sua escrita.

Assim tanto Ribeiro quanto Barreto se revelam insurgentes e combatentes dos atrozes vividos pelos negros em solo brasileiro, cada autor em sua época, mas trazendo reflexões sociorrraciais que se fazem atuais e pertinentes para nossa era globalizada e tecnológica. Dessa maneira, ambos os autores convergem para uma mesma luta, ainda que ajam sobre formas diferentes.

\section{REFERÊNCIAS}

ALTHUSSER, L. Aparelhos ideológicos de estado: nota sobre os aparelhos ideológicos de estado (AIE). Tradução Walter José Evangelista e Maria Laura Viveiros de Castro. Rio de Janeiro: Graal, 1983.

BARRETO, Lima. Clara dos Anjos. 11ª ed. São Paulo: Ática, 1998.

BARRETO, Lima. Bagatelas. São Paulo: Brasiliense, 1956.

BOSI, Alfredo. História Concisa da Literatura Brasileira. São Paulo: Cultrix, 1970. 
CADERNOS NEGROS 8. Organização Quilombhoje. São Paulo: Edição dos autores, 1985. p. 7-8.

COURTINE, J.-J.; MARANDIN, J.M. Quel objet pour l'analise du discourse. Lille: Press Universitaires de Lille, 1981.

FERNANDES, F. O negro no mundo dos brancos. São Paulo: Difusão Europeia do Livro, 1972.

HOLANDA, Sérgio Buarque de. Raízes do Brasil. 26a . ed. São Paulo: Companhia das Letras, 1995.

LINS, Osman. Lima Barreto e o espaço romanesco. São Paulo: Ática, 1976.

MEMMI, Albert. Retrato do colonizado precedido pelo retrato do colonizador. Trad. Bras. $2^{\text {a }}$. ed. Rio de Janeiro: Paz e Terra, 1977.

MARTINS, Leda. A fina lâmina da palavra. O eixo e a roda, v. 15, 55-83, 2007. Disponível em: http://www.letras.ufmg.br/poslit.

NEVES, José Eugênio das. Esmeralda Ribeiro e Lima Barreto: um diálogo em segredos. In: Terra roxa e outras terras. Revista de estudos literários, v. 17B, 49-59, dez. 2009.

ORLANDI, E.P. Análise de discurso. Em: ORLANDI, E.P.; LAGAZZI-RODRIGUES, S. (Orgs.). Introdução às ciências da linguagem - discurso e textualidade. Campinas: Pontes Editores, 2010. p. 11-33.

Exterioridade e ideologia. Cad. Est. Ling., Campinas, v. 30, 27-33, jan.-jun. 1996.

PRADO, Antonio Arnoni. Lima Barreto Personagem de João Antônio. Novos Estudos, $\mathrm{n}^{\circ} 54$, v. 3, 73-84, jul.1999.

PORTAL UFMG. Literatura Afro-Brasileira. Disponível em: www.letras.ufmg.br/literafro. Acesso em 10 set. 2014.

PÊCHEUX, M. Semântica e discurso: uma crítica à afirmação do óbvio. Trad. Bras. São Paulo: Unicamp, 1997.

RABASSA, Gregory. O negro na ficção brasileira: meio século de história literária. Rio de Janeiro: Edições Tempo Brasileiro, 1965.

RIBEIRO, Esmeralda. Guarde Segredo. Em: Cadernos Negros: Os Melhores Contos [Org. Quilombhoje]. São Paulo: Ministério da Cultura, 1998.

SCHWARCZ, Lília Moritz. O espetáculo das raças: cientistas, instituições e questão racial no Brasil - 1870-1930. São Paulo: Companhia das Letras, 1993.

SILVA, Adriana dos Reis. As relações interétnicas brasileiras: uma análise da construção discursiva de Clara dos Anjos e Fera Ferida. Tese. Doutorado em Língua Portuguesa e 
Linguística, Pontifícia Universidade Católica de Minas Gerais, Programa de PósGraduação em Letras, Belo Horizonte, 2014.

Artigo recebido em: dezembro de 2017.

Aprovado e revisado em: março de 2018.

Publicado em: maio de 2018.

\section{Para citar este texto:}

SILVA, Adriana dos Reis. A racialização pelas vozes das personagens de Lima Barreto e Esmeralda Ribeiro e(m) uma análise discursiva. Entremeios [Revista de Estudos do Discurso, ISSN 2179-3514, on-line, www.entremeios.inf.br], Seção Temática [Discurso, arte e literatura - Parte I], Programa de Pós-Graduação em Ciências da Linguagem (PPGCL), Universidade do Vale do Sapucaí (UNIVÁS), Pouso Alegre (MG), vol. 16, p. 373-389, jan. - jun. 2018.

DOI: http://dx.doi.org/10.20337/ISSN2179-3514revistaENTREMEIOSvol16pagina373a389 